\title{
Treatment for gender dysphoria in children: the new legal, ethical and clinical landscape
}

\section{Medical \\ practitioners \\ should benefit \\ from an \\ understanding \\ of the recent \\ developments \\ in legal \\ principles}

Malcolm K Smith PhD, LLM, LLB(Hons)

Ben Mathews

$\mathrm{PhD}, \mathrm{LLB}, \mathrm{BA}$

Queensland University of Technology,

Brisbane, QLD.

mk.smith@qut.edu.au

doi: 10.5694/mja14.00624

Online first 27/01/15
G ender dysphoria is a serious condition in which a child's subjectively felt identity and gender are not congruent with her or his biological sex, causing clinically significant distress or impairment in social functioning or other important areas of functioning. Over the past 10 years, the Family Court of Australia has received an increasing number of applications seeking authorisation for the commencement of hormone therapy to treat children diagnosed with gender dysphoria. ${ }^{1-11}$

Treatment of children with gender dysphoria is given in two stages. Stage 1 treatment involves the provision of puberty blocking medication, and stage 2 comprises cross-sex hormone treatment. Until very recently, courts considered both stages of treatment together and regarded them at law as a form of special medical procedure, which can only be lawfully performed with court approval. In a significant recent development, courts have drawn a distinction between the two stages of treatment, permitting parents to consent to stage 1 treatment. In addition, it has been held that a child who is determined by a court to be Gillick competent can consent to stage 2 treatment. A Gillick-competent child is one who is found to possess sufficient understanding and intelligence to enable her or him to understand fully what is proposed.${ }^{12}$ Medical practitioners working in this field require an understanding of these principles, so that they know when and why they must obtain court approval before conducting treatment.

In this article, we outline the nature of gender dysphoria and its treatment, explain the legal principles regarding special medical procedures, and analyse the recent legal developments concerning treatment for gender dysphoria. These developments make substantial changes to the previous legal position about who can consent to both stages of treatment for gender dysphoria, and have important ethical, clinical and practical implications for medical practitioners in this field.

\section{Gender dysphoria in children and treatment for the condition}

A number of changes in the definition of the condition of gender dysphoria, previously generally referred to as gender identity disorder, have been made in the most recent version of the Diagnostic and statistical manual of mental disorders..$^{13,14}$ According to the updated definition, gender dysphoria is a condition which lasts for at least 6 months. A child must feel, and must verbalise, a strong desire to be of the other gender. ${ }^{14}$ In diagnostic terms, there is a strong, clear and persistent difference between the individual's expressed and or experienced gender and the gender that others would assign her or him. Due

\section{Summary}

- Gender dysphoria is a condition in which a child's subjectively felt identity and gender are not congruent with her or his biological sex. Because of this, the child suffers clinically significant distress or impairment in social functioning.

- The Family Court of Australia has recently received an increasing number of applications seeking authorisation for the provision of hormones to treat gender dysphoria in children.

- Some medical procedures and interventions performed on children are of such a grave nature that court authorisation must be obtained to render them lawful. These procedures are referred to as special medical procedures.

- Hormonal therapy for the treatment of gender dysphoria in children is provided in two stages occurring years apart. Until recently, both stages of treatment were regarded by courts as special medical treatments, meaning court authorisation had to be provided for both stages.

- In a significant recent development, courts have drawn a distinction between the two stages of treatment, permitting parents to consent to the first stage. In addition, it has been held that a child who is determined by a court to be Gillick competent can consent to stage 2 treatment.

- The new legal developments concerning treatment for gender dysphoria are of ethical, clinical and practical importance to children and their families, and to medical practitioners treating children with gender dysphoria. Medical practitioners should benefit from an understanding of the recent developments in legal principles. This will ensure that they have up-to-date information about the circumstances under which treatment may be conducted with parental consent, and those in which they must seek court authorisation.

to the mismatch between biological sex and perceived identity, those with gender dysphoria may experience profound psychological and physical tensions, and may have difficulties with socialisation. Consequently, it is common for those with gender dysphoria to have psychological symptoms including anxiety and depression, to self-harm, and to have suicidal ideation. ${ }^{15}$ The condition is not characterised by genetic, anatomical or hormonal abnormalities. ${ }^{16}$ When gender dysphoria intensifies with the onset of puberty, it will seldom subside. ${ }^{17}$

Treatment for gender dysphoria involves two stages of hormonal therapy, accompanied by psychological treatment that commences well in advance. ${ }^{18}$ Stage 1 of treatment involves administration of hormones such as 
1 Established principles relevant to determining whether a form of treatment is regarded as a special medical procedure

- In Marion's case, ${ }^{19}$ it was held that court authorisation must be obtained in circumstances where a procedure performed on a minor is regarded as nontherapeutic, and where:

- there is a significant risk of making the wrong decision without court involvement;

- the procedure in question has particularly grave consequences;

t the procedure is irreversible and invasive; and

- there is potential for conflict in terms of the interests of the parties involved (eg, parents, clinicians and patient).

- Case law has established that routine or necessary medical care concerning children falls within the ambit of parental decision making when the treatment is intended to serve a therapeutic purpose. ${ }^{5}$ This is so even in cases where grave consequences may flow from the provision of such medical care ${ }^{20}$ or when the medical treatment is regarded as experimental. ${ }^{21}$

gonadotropin-releasing hormone analogues, to prevent the onset of puberty in the child's biological sex, and has been administered to children as young as 10 years old. Stage 1 treatment is reversible, as puberty in the child's biological sex will continue if the treatment is stopped. The second stage of treatment is administered when the child is slightly older - around the age of 16 years. Stage 2 treatment involves, for example, the administration of oestrogen or testosterone for the purpose of encouraging the development of physical characteristics in the sex with which the child psychologically identifies. The effects of stage 2 treatment are more serious than the first and are considered to be irreversible.

Subsequently, surgery for gender reassignment can occur, if required, usually once the individual is an adult (surgical intervention that is contemplated before a child reaches 18 years of age would require additional court approval). Once diagnosed, early treatment for gender dysphoria appears to optimise psychological and social development, as well as subsequent modifications to the child's physical appearance. ${ }^{18}$

\section{Legal principles relevant to consent for} treatment of gender dysphoria in children

\section{Consent and special medical procedures}

A child's parents generally have power to consent to their child's medical treatment. Under s 61C of the Family Law Act 1975 (Cwlth), each parent of a child aged under 18 years has parental responsibility for the child. Parental responsibility is defined in s 61B to include "all the duties, powers, responsibilities and authority which, by law, parents have in relation to children", and this includes the right to consent to the child's medical treatment in most cases (Box 1). This right must be exercised in accordance with a child's best interests, and s 60CC outlines the factors that a court will consider when determining these.

This general parental power has limits. Notably, in the landmark decision of Marion's case, ${ }^{19}$ the High Court of Australia referred to key principles to explain why some medical procedures fall outside the scope of parental consent, and instead require court approval. The High Court held that the parents of an intellectually disabled girl were unable to consent to a non-therapeutic sterilisation procedure. The non-therapeutic nature of the treatment was emphasised as a reason for requiring court authorisation, together with the procedure being considered to be major, invasive and irreversible (Box 1). Court approval was seen as a necessary safeguard. ${ }^{22}$

In special medical procedures, authorisation can be granted by the Supreme Court in its parens patriae jurisdiction, or by the Family Court under the Family Law Act. Section $67 Z \mathrm{ZC}$ provides the Family Court with the authority to make orders relating to the welfare of children, which includes special medical procedures. The Family Law Rules 2004 complement s 67ZC. In particular, rule 4.09 sets out the process for providing evidence to satisfy the court that the medical procedure is in the child's best interests. The factors set out in the Family Law Rules closely follow the list of matters articulated by Nicholson CJ in Re Marion (No 2) (1994) FLC 92-448.

\section{Authorisation for medical treatment: who can consent, to what, and why}

In 2004, the Family Court in Re Alex determined that treatment for childhood gender identity disorder (as the condition was then described) was non-therapeutic and fell outside the boundaries of parental consent; it was a special medical procedure requiring court authorisation. ${ }^{1}$

Since 2004, an increasing number of applications have been made to the Family Court concerning treatment for gender dysphoria..$^{2-11}$ This indicates not only the relevance of the issue to patients, clinicians and the community, but it may also suggest a level of unmet clinical need. In a series of recent decisions, the Family Court has adopted a different approach to Re Alex in classifying treatment for gender dysphoria as special. This has reshaped the ethical, clinical and practical basis for making decisions regarding stage 1 treatment. It has also resulted in a significant change to the basis for stage 2 treatment. The key developments are as follows.

In 2013 in Re Lucy, it was held that treatment for gender dysphoria is therapeutic treatment because it is administered primarily to ameliorate a psychiatric disorder. The court also held that parents are lawfully permitted to consent to stage 1 treatment, as it is reversible. The same conclusion was reached several weeks later in the case of Re Sam and Terry, ${ }^{9}$ which reiterated that stage 1 treatment carried only a low risk of error from misdiagnosis and did not present grave consequences. However, in both decisions it was held that stage 2 treatment requires court authorisation because of its irreversible effects and the significant risk of making a wrong decision about a child's present or future capacity to consent. The consequences of stage 2 treatment were noted to be particularly grave, as physical changes would result from the hormone therapy in line with the change in gender. The court concluded that the correct approach to determining whether court authorisation is required involves not only classifying the treatment as therapeutic but also assessing its potential 
2 Do recent cases concerning treatment for gender dysphoria change established principles relating to special medical treatments?

- Previous Family Court decisions have allowed parents to consent to serious, invasive and irreversible medical procedures where there is a potential therapeutic benefit (Box 1). Recent jurisprudence concerning treatment for gender dysphoria has determined that hormonal treatment for the condition is therapeutic; a conclusion that is presumably applicable to both stages of treatment. However, court approval is required for stage 2 treatment because of its irreversible and serious consequences.

- The approach adopted in recent cases appears to depart from the principles set out in Marion's case, ${ }^{19}$ which regard therapeutic interventions as falling within the realms of parental consent (Box 1). However, based on the reasoning in recent cases, $^{8-11}$ classification of a specific treatment as special does not appear to rest solely on the therapeutic-non-therapeutic distinction, but on an assessment of all of the factors outlined in Marion's case. Where there is concern about the nature and effect of a particular treatment, the law may nevertheless impose a requirement to obtain court approval, even where the treatment is regarded as therapeutic. Australian courts may later develop new categories of special medical procedures or interventions, which might include other types of therapeutic treatment. However, at present there are a number of established categories of special medical procedures, and parental consent alone is not sufficient for these different categories of treatment.

consequences in the terms described by the High Court in Marion's case (Box 1).

After these two decisions by single judges, the Full Court of the Family Court heard an appeal in Re Jamie ${ }^{10}$ in 2013 concerning parental consent to treatment for gender dysphoria. This decision is important as it has higher precedential value than the single judge decisions, binding future decisions by lower courts. The Full Court affirmed the position adopted in Re Lucy and Re Sam and Terry, holding that parental power to consent to the child's medical treatment extends to stage 1 treatment for gender dysphoria, while court authorisation is required for stage 2 treatment..$^{10}$ The court's decision centred on the reversibility of stage 1 treatment and the irreversibility of stage 2 and was therefore clearly underpinned by the factors outlined by the High Court in Marion's case (Box 1). The decision of the Full Court in Re Jamie was followed in November 2013 in Re Shane. ${ }^{11}$

Parents can therefore lawfully consent to a child's stage 1 treatment for gender dysphoria. This is consistent with existing legal principles concerning parental authority and promotes autonomy and beneficence for the child. It is also logistically superior for clinicians, parents and children, rather than having to seek court authority with attendant cost, delay and inconvenience. However, stage 2 treatment for gender dysphoria must still be approved by a court, despite being regarded as therapeutic. ${ }^{10} \mathrm{On}$ one view, this is an unnecessary incursion into parental power, which normally extends to therapeutic treatments. On another view, there is value in the court retaining its power to authorise stage 2 treatment as a procedural safeguard, because of the complexity of this condition and the relevance of the principles articulated in Marion's case (Box 2).

\section{Decision making by mature minors in relation} to special medical procedures

There is a further important aspect of the decision in $R e$ Jamie. The principle of Gillick competence (approved by the High Court in Marion's case) was considered by the Full Court of the Family Court in Re Jamie to determine whether a Gillick-competent minor could consent to stage 2 treatment and, if so, by what mechanism (which may also extend to circumstances where legislation provides the minor with a right to make the decision for him or herself, such as in South Australia's Consent to Medical Treatment and Palliative Care Act 1995). The Full Court determined that a Gillick-competent minor is able to provide consent to stage 2 treatment. However, Bryant $\mathrm{CJ}$ imposed the requirement that the parties make an application to the court for determination of whether the child is Gillick competent.

This is a significant change in principle, enabling children deemed competent by the court, to consent to this type of medical treatment. Recognition of the mature minor's right to consent is a sound development, sitting squarely with the fundamental legal principle in Gillick ${ }^{12}$ and being ethically consistent with promoting the autonomous wishes of a full moral agent. Additionally, it reposes the decision about the child's competence in the court, whereas medical practitioners are ordinarily responsible for determining the minor's competency. This aspect of the decision was also confirmed in the subsequent case of Re Shane.

\section{Conclusion}

The recent case law developments concerning treatment for gender dysphoria confirm that parents are lawfully able to consent to the first stage of hormonal treatment on behalf of their children, but that court involvement is required as part of the consent process for stage 2 treatment. In addition, when a minor possesses a sufficient understanding of the nature and consequences of stage 2 treatment, she or he has legal capacity to consent to that aspect of treatment, but the finding of competency must be made by a court.

The growth in applications for approval to treat gender dysphoria suggests a level of unmet need - a phenomenon also apparent in the United States. ${ }^{23}$ The new legal landscape in Australia for treatment for gender dysphoria is therefore of current, and growing, importance for practitioners and individuals with this condition. Increased awareness of treatment possibilities, the benefits of early intervention, and of the legal framework, would be beneficial.

Competing interests: No relevant disclosures.

Provenance: Not commissioned; externally peer reviewed. 
1 Re Alex (2004) 31 Fam LR 503.

2 Re Brodie (Special Medical Procedure) [2008] FamCA 334.

3 Re Bernadette [2010] FamCA 94.

4 Re O (Special Medical Procedure) [2010] FamCA 1153.

5 Re Sean and Russell (Special Medical Procedures) [2010] FamCA 948.

6 Re Rosie (Special Medical Procedure) [2011] FamCA 63.

7 Re Jodie [2013] FamCA 62.

8 Re Lucy [2013] FamCA 518.

9 Re Sam and Terry [2013] FamCA 563.

10 Re Jamie [2013] FamCACF 110.

11 Re Shane [2013] FamCA 864.

12 Gillick $v$ West Norfolk and Wisbech Area Health Authority [1986] $\mathrm{AC} 112$.

13 Zucker KJ, Cohen-Kettenis PT, Drescher J, et al. Memo outlining evidence for change for gender identity disorder in the DSM-5. Arch Sex Behav 2013; 42: 901-914.

14 American Psychiatric Association. Diagnostic and statistical manual of mental disorders. 5th ed. Arlington, Va: APA, 2013. dsm.psychiatryonline.org (accessed Apr 2014).

15 Grossman AH, D'Augelli AR. Transgender youth and lifethreatening behaviors. Suicide Life Threat Behav 2007; 37: 527-537.
16 Hembree WC, Cohen-Kettenis P, Delemarre-van de Waal $\mathrm{HA}$, et al. Endocrine treatment of transsexual persons: an Endocrine Society clinical practice guideline. J Clin Endocrinol Metab 2009; 94: 3132-3154.

17 Zucker KJ. The DSM diagnostic criteria for gender identity disorder in children. Arch Sex Behav 2010; 39: 477-498.

18 Delemarre-van de Waal HA, Cohen-Kettenis PT. Clinical management of gender identity disorder in adolescents: a protocol on psychological and paediatric endocrinology aspects. Eur J Endocrinol 2006; 155: S131-S137. doi: 10.1530/ eje.1.02231.

19 Department of Health and Community Services (NT) v JWB (Marion's case) (1992) 175 CLR 218.

20 Re Baby D (No 2) [2011] FamCA 176.

21 Re Baby $A$ [2008] FamCA 417.

22 Naik L. When is the sterilisation of an intellectually disabled child "therapeutic"? A practical analysis of the legal requirement to seek court authorisation. J Law Med 2012; 20: 453-463.

23 Spack NP, Edwards-Leeper L, Feldman HA, et al. Children and adolescents with gender identity disorder referred to a pediatric medical center. Pediatrics 2012; 129: 418-425. 